\title{
Transplant arteriosclerosis in humanized mice reflects chronic lung allograft dysfunction and is controlled by regulatory $T$ cells
}

Thierry Siemeni, MD, ${ }^{\mathrm{a}}$ Ann-Kathrin Knöfel, PhD, ${ }^{\mathrm{a}, \mathrm{b}}$ Fabio Ius, MD, ${ }^{\mathrm{a}, \mathrm{b}}$ Wiebke Sommer, MD, ${ }^{\mathrm{a}, \mathrm{b}}$ Jawad Salman, MD, ${ }^{a}$ Dietmar Böthig, MD, ${ }^{a}$ Christine S. Falk, $\mathrm{PhD},{ }^{\mathrm{c}}$ Igor Tudorache, MD, Axel Haverich, MD, ${ }^{a, b}$ and Gregor Warnecke, $\mathrm{MD}^{\mathrm{a}, \mathrm{b}}$

\section{ABSTRACT}

Objective: Chronic lung allograft dysfunction (CLAD) is a severe complication of lung transplantation limiting long-term survival. We studied correlations between CLAD after clinical lung transplantation and leukocyte-mediated development of transplant arteriosclerosis (TA) in a humanized mouse model. The pericardiophrenic artery was procured from surplus tissue of donor lungs $(\mathrm{n}=22)$ transplanted in our clinical program and was implanted into the abdominal aorta of immune-deficient mice.

Methods: Allogeneic human peripheral blood mononuclear cells (PBMCs) had been procured 1 day after lung transplantation from the respective recipients with or without enriching for $\mathrm{CD} 4{ }^{+} \mathrm{CD} 25^{\text {high }} \mathrm{T}$ cells were used. TA was assessed in mice 28 days later by histology. The respective clinical lung recipients were later divided into 2 groups. Eight patients $(36.3 \%)$ had developed CLAD $23 \pm 5$ months after lung transplantation, whereas the remaining $14(63.6 \%)$ did not develop CLAD within $25 \pm 5$ months.

Results: In the PBMC CLAD+ group of mouse experiments, TA was significantly more severe than in the PBMC CLAD- group $(39.9 \% \pm 13 \%$ vs $14.9 \% \pm 4 \%$ intimal thickening; $P=.0081)$. Then, intimal thickening was significantly inhibited in the PBMC + regulatory $\mathrm{T}$ cells CLAD + group compared with the PBMC CLAD + group $(0.4 \% \pm 4 \%$ vs $39.9 \% \pm 13 \% ; P=.003)$. In the experiments using PBMCs from lung recipients without CLAD, enriching regulatory $\mathrm{T}$ cells also suppressed the development of TA $(0.9 \% \pm 3 \%$ PBMC CLAD- vs $14.9 \% \pm 4 \%$ PBMC + regulatory T cells CLAD-; $P=.001)$.

Conclusions: Lung transplant recipients who later develop CLAD have peripheral leukocytes already at the time of transplant that transfer proinflammatory properties leading to TA in a humanized mouse model. TA remains sensitive to inhibition by autologous regulatory $\mathrm{T}$ cells, suggesting a cell therapy-based approach for the prevention of CLAD after lung transplantation. (J Thorac Cardiovasc Surg 2019;157:2528-37)

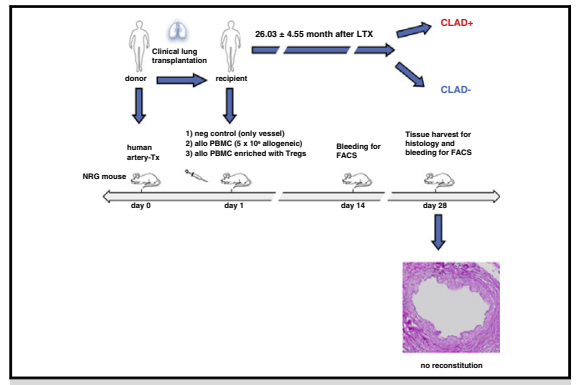

In vivo development of transplant arteriosclerosis reflects CLAD development.

\section{Central Message}

Lung transplant recipients who later develop CLAD have peripheral leukocytes already at the time of transplant that transfer proinflammatory properties leading to TA in a humanized mouse model.

\section{Perspective}

A cell therapy-based approach for the prevention of CLAD after lung transplantation could be developed.

See Commentaries on pages 2538 and 2540.
Long-term survival after lung transplantation is compromised by the development of chronic lung allograft dysfunction (CLAD), resulting from recurrent and

From the a Division of Cardiac, Thoracic, Transplantation, and Vascular Surgery, ${ }^{b}$ German Centre for Lung Research BREATH site, and ${ }^{c}$ IFB-Tx, Hannover Medical School, Hannover, Germany.

Supported by grants from the Deutsche Forschungsgemeinschaft (SFB 738, B3), the MHH Young Faculty Program, the German Center for Infectious Diseases (DZIF, TTU-IICH 08.701), and the German Center for lung research (Biomedical Research in End-Stage and Obstructive Lung Disease Hannover [BREATH]).

Drs Siemeni and Knöfel contributed equally to this work.

Read at the 97th Annual Meeting of The American Association for Thoracic Surgery, Boston, Massachusetts, April 29-May 3, 2017. compounding alloimmune infections and other insults and is characterized by neutrophil inflammation, fibrosis, respiratory failure, and death. Ten-year survival following

Received for publication May 22, 2017; revisions received Jan 4, 2019; accepted for publication Jan 6, 2019; available ahead of print April 5, 2019.

Address for reprints: Gregor Warnecke, MD, Division of Cardiac, Thoracic, Transplantation, and Vascular Surgery, Hannover Medical School, Carl-Neuberg-Str 1, 30625 Hannover, Germany (E-mail: warnecke.gregor@mh-hannover.de). 0022-5223/\$36.00

Copyright (C) 2019 Published by Elsevier Inc. on behalf of The American Association for Thoracic Surgery

https://doi.org/10.1016/j.jtcvs.2019.01.134 

Abbreviations and Acronyms
BAL = bronchoalveolar lavage
BOS = bronchiolitis obliterans syndrome
$\mathrm{CD}=$ cluster of differentiation
CLAD $=$ chronic lung allograft dysfunction
$\mathrm{NRG}=\mathrm{NOD} \cdot \mathrm{rag}^{-/-} \gamma \mathrm{c}^{-/-}$mice
$\mathrm{PBMC}=$ peripheral blood mononuclear cell
Qint $=$ quotient for the thickness of the intima
$\mathrm{TA}=$ transplant arteriosclerosis
Treg $=$ regulatory $\mathrm{T}$ cells

Scanning this QR code will

take you to the article title page to access supplementary information.

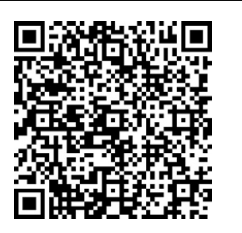

transplantation is only $30 \%$ to $40 \%$ in international registries, with CLAD explaining much of this mortality, and has changed little over 3 decades. ${ }^{1-5}$ CLAD is defined as an irreversible decline in forced expiratory volume in 1 second or/and in forced vital capacity of at least $20 \%$ compared with the mean of the 2 best postoperative values. ${ }^{2,4,6}$ Clinical effects of CLAD occur largely beyond the first year after transplantation, prompting further questions regarding its early manifestations. ${ }^{7}$ Transplant arteriosclerosis (TA) is characterized by intimal hyperplasia and vasomotor dysfunction that develops as a result of immunologic targeting of vascular endothelial and smooth muscle cells. ${ }^{8,9}$ TA is driven by alloimmune targeting of the graft vasculature because intimal thickening is confined to the graft and does not develop in experimental models in which grafts are placed in genetically identical animals or in recipients that lack adaptive immune responses. ${ }^{10} \mathrm{TA}$ is the hallmark of chronic rejection. ${ }^{11} \mathrm{We}$ previously have shown that alloantigen priming in clinical lung transplant recipients leads to more severe TA in a humanized mouse model. ${ }^{12}$ Notable efforts have been made to relate cytokines and other biomarkers such as profibrotic mediators, oxidative biomarkers, donor-specific antibodies, and biomarkers of gastroesophageal reflux to lung allograft rejection, yet none apart from bronchoalveolar lavage (BAL) neutrophilia are being used clinically. ${ }^{13-15}$

To study these early events in CLAD development, we aimed to use a humanized mouse model enabling the investigation of immune cells from lung transplantation recipients. Here, we correlate the vivo development of TA in humanized mice with the later CLAD development of clinical lung transplantation recipients.
We hypothesized that in vivo development of TA in humanized mice reflects the later development of CLAD and aim at studying properties of regulatory $\mathrm{T}$ cells (Treg) to inhibit these alloresponses.

\section{MATERIALS AND METHODS Patients}

Consecutive recipients of bilateral lung transplantation were included in the study protocol, providing transplantable small donor arteries. Written consent was obtained from all recipients for collecting tissue samples, drawing additional blood samples, and monitoring clinical data. The ethics committee of Hannover Medical School approved the study (No. 122-2007). The Animal Welfare Organisation approved the study as well (12-0982; 07-1359). All patients with corresponding animal experiments were included in the final analysis $(\mathrm{n}=22)$. Basic demographic and perioperative data on the patients are given in Table 1.

\section{Procurement of Human Arteries}

Human arteries for transplantation were procured from surplus tissue of cadaver donor lungs. Segments of the pericardiophrenic artery were dissected while lungs were implanted in the respective recipients and then stored in heparinized normal saline solution at $4^{\circ} \mathrm{C}$.

\section{Experimental Animals}

NODrag $^{-1-} / \mathrm{IL}-2 \mathrm{r} \gamma \mathrm{c}^{-1-}$ (NRG) mice were donated by Dale Greiner, University of Massachusetts, Worcester, Mass. Mice were housed in isolators under specific pathogen-free conditions. NRG mice are devoid of functional B cells, T cells, or natural killer cells and regularly show good engraftment of human peripheral blood mononuclear cells (PBMCs). Animals used for experiments were aged 8 to 12 weeks at the time of surgery. All animals received humane care in compliance with German animal protection legislation, the Principles of Laboratory Animal Care, and the Guide for the Care and Use of Laboratory Animals.

\section{Surgical Technique}

Aortic interposition grafts in mice were performed with the human pericardiophrenic artery implanted into the infrarenal abdominal aorta of NRG mice using a technique originally described by Koulack and colleagues (Video 1). ${ }^{16}$

\section{Preparation of Human PBMCs and Adoptive Transfer}

PBMC were prepared from whole blood drawn from the respective lung recipients at the day of transplantation by gradient centrifugation (FicollPaque; GE Healthcare, Berlin, Germany). After red cell lysis and 2 washes in phosphate buffered saline, cells were counted and adjusted to $5 \times 10^{6} \%$ $500 \mu$ L RPMI 1640 (ThermoFisher Scientific Inc, Waltham, Mass), for intraperitoneal injection into host mice. Animals were reconstituted with $5 \times 10^{6}$ human PBMCs according to the experimental protocol on day 1 following artery transplantation.

\section{Sorting of Human T Cells}

Total human PBMCs were isolated as described above and resuspended in RPMI 1640 + magnetic-activated cell sorting buffer. Cells were labeled with antihuman CD4-APC and antihuman CD25-PE (both Miltenyi Biotec $\mathrm{GmbH}$, Bergisch Gladbach, Germany) and subsequently sorted on a FACSAria cell sorter (BD, Heidelberg, Germany). The gate for sorting was set at the $\mathrm{CD} 4{ }^{+} \mathrm{CD} 25^{\text {high+ }}$ population. Upon reanalysis, cluster of differentiation $(\mathrm{CD}) 4^{+} \mathrm{CD} 25^{\text {high }} \mathrm{T}$ cell populations were $>95 \%$ pure. 
TABLE 1. Demographic and perioperative characteristics of patients with $(+)$ or without $(-)$ chronic lung allograft dysfunction (CLAD)

\begin{tabular}{lccl}
\hline \multicolumn{1}{c}{ Characteristic } & CLAD + & CLAD- & $\boldsymbol{P}$ value \\
\hline Male (n) & 6 & 6 & NS \\
Female (n) & 5 & 5 & NS \\
Age (y) & $33.0 \pm 17.2$ & $55.0 \pm 11.7$ & NS \\
Transplant indication & & & \\
$\quad$ COPD & 2 & 2 & NS \\
$\quad$ Pulmonary fibrosis & 3 & 5 & NS \\
$\quad$ Cystic fibrosis & 4 & 5 & NS \\
$\quad$ Sarcoidosis & 1 & 0 & NS \\
Invasive mechanical & $10.0 \pm 8.02$ & $14.5 \pm 16.8$ & NS \\
$\quad$ ventilation (h) & & & \\
Intensive care unit stay & $2 \pm 1.5$ & $2 \pm 17.1$ & NS \\
Postoperative DSA & 3 & 6 & NS \\
$\quad$ HLA I & 4 & 2 & NS \\
$\quad$ HLA II & 5 & 3 & NS \\
Infection and colonization & 0 & 0 & NS \\
$\quad$ with microorganisms & & & \\
\hline Primary graft dysfunction & 3 & 2 & NS \\
\hline
\end{tabular}

Values are presented as $\mathrm{n}$, or mean \pm standard deviation. $C L A D$, Chronic lung allograft dysfunction; $N S$, not significant; $C O P D$, chronic obstructive pulmonary disease; $D S A$, donor-specific antibodies; $H L A$, human leukocyte antigen.

\section{Experimental Groups}

Mouse cohorts bearing human artery grafts from the same donor were assigned to the following 3 groups: negative control animals without reconstitution with allogeneic human PBMC (negative control); experimental animals receiving $5 \times 10^{6}$ allogeneic human nonmodified PBMC; animals receiving $5 \times 10^{6}$ allogeneic $\mathrm{PBMC}$ enriched with 1.15 to $4.8 \times 10^{5}$ $\mathrm{CD} 4^{+} \mathrm{CD} 25^{\text {high }} \mathrm{T}$ cells (PBMC CD4/CD25 enriched). The Treg to PBMC ratio used was previously established in a similar humanized mouse model. ${ }^{12}$ In case more than 3 mice were available, replicates of the groups were designated. The experimental setup is shown in Figure 1.

\section{Engraftment Control}

Human PBMC engraftment in NRG mice was assessed by fluorescence-activated cell sorting analysis of peripheral blood 14 and

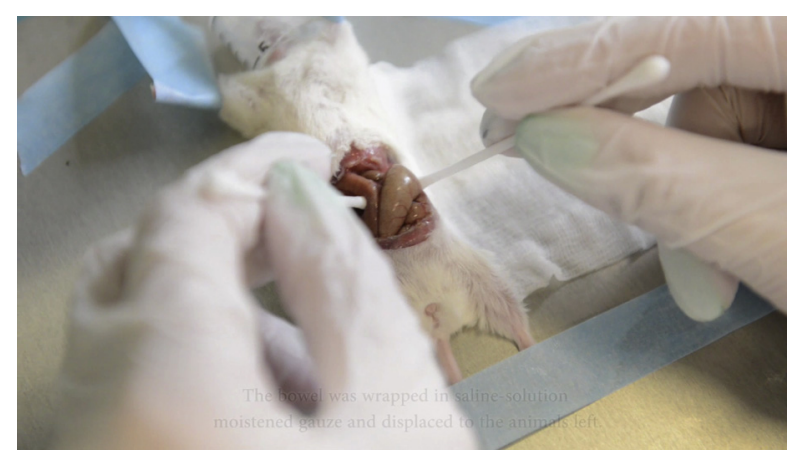

VIDEO 1. Transplantation of human artery in NRG mice. Video available at: https://www.jtcvs.org/article/S0022-5223(19)30519-7/fulltext.
28 days after intraperitoneal injection of human cells. Whole blood samples were stained with allophycocyanin-conjugated antimurine CD45 monoclonal antibody (clone 30-F11; Biolegend, San Diego, Calif) and phycoerythrin-conjugated antihuman CD45 monoclonal antibody (clone HI30; BD). Successful engraftment was defined as the presence of any percentage of human $\mathrm{CD}^{+} 5^{+}$leukocytes in PBMC after 14 days as well as $>1 \%$ human CD45+ leukocytes in PBMC after 28 days as defined earlier. ${ }^{8}$ All experimental animals finally included into analyses met these criteria.

\section{Analysis of the Arterial Interposition Graft}

Human arteries were harvested from the mice 28 days after transplantation. The grafts were fixed in formalin and embedded in paraffin. Sections of 2- to 3- $\mu \mathrm{m}$ thickness were cut and stained with hematoxylin and eosin and Elastica-van-Gieson stain. Morphometric analysis of TA was performed on Elastica-van-Gieson-stained sections. Histologic pictures were taken at $\times 40$ magnification using a digital camera system (Keyence Deutschland GmbH, Neu-Isenburg, Deutschland). Digitized images were then analyzed using Photoshop software version 7.0 (Adobe, San Jose, Calif). The areas within the lumen of the vessel, within the internal elastic lamina and within the external elastic lamina were circumscribed and the respective absolute pixel counts of the area were recorded. The areas within the lumen of the vessel and within the internal elastic lamina were circumscribed and the respective absolute pixel counts recorded. From these measurements, the quotient for the thickness of the intima (Qint) was calculated. The Qint indicates relative thickness (\%) of the intima or \% luminal occlusion $(\mathrm{Qint}=$ intima/[lumen + intima] $\times 100)$. For quantitative comparisons between the experimental groups, the minor luminal obstruction elicited in negative control grafts was always subtracted from all experimental measurements within the respective experimental cohorts, controlling for preexisting endothelial damage, varying cold ischemic times.

\section{Sampling and Analysis of Mouse Plasma}

Heparinized mouse blood was collected 28 days after transplantation and centrifuged for $4 \mathrm{~min}$ at $3000 \mathrm{~g}$, plasma was separated and stored at $-80^{\circ} \mathrm{C}$. Plasma cytokine and chemokine concentrations were quantified by multiplex protein arrays, according to the manufacturer's instructions (BioRad Laboratories, Hercules, Calif) using a technique originally described by Braun and colleagues. ${ }^{17}$

\section{Statistical Analysis}

All data were reported as mean \pm standard error of the mean. Statistical analyses were performed using GraphPad Prism version 4.03 (GraphPad Software Inc, San Diego, Calif). For comparisons among the groups, the Mann-Whitney $U$ test or analysis of variance were used.

\section{RESULTS}

\section{Enrichment of Tregs in PBMCs of Lung Recipients and Reconstitution of NRG Mice}

NRG mice bearing arteries were reconstituted intraperitoneally with $5 \times 10^{6}$ recipient $\mathrm{PBMC}$ at day 0 (PBMC group). In the $\mathrm{CD} 4 / 25$ enriched (Treg) group, putative Treg sorted for CD4 and high levels of CD25 were added at $1.05-5.4 \times 10^{5}$ cells to $5 \times 10^{6}$ PBMC per animal. Before transfer into NRG mice, this admixture resulted in increased percentages of $\mathrm{CD} 4{ }^{+} \mathrm{CD} 25^{\text {high }} \mathrm{T}$ cells in PBMC from $1.1 \%$ to $3.9 \%$ in representative fluorescenceactivated cell sorting assays (Figure 2). We previously described this method in Siemeni and colleagues. ${ }^{12}$ Human 


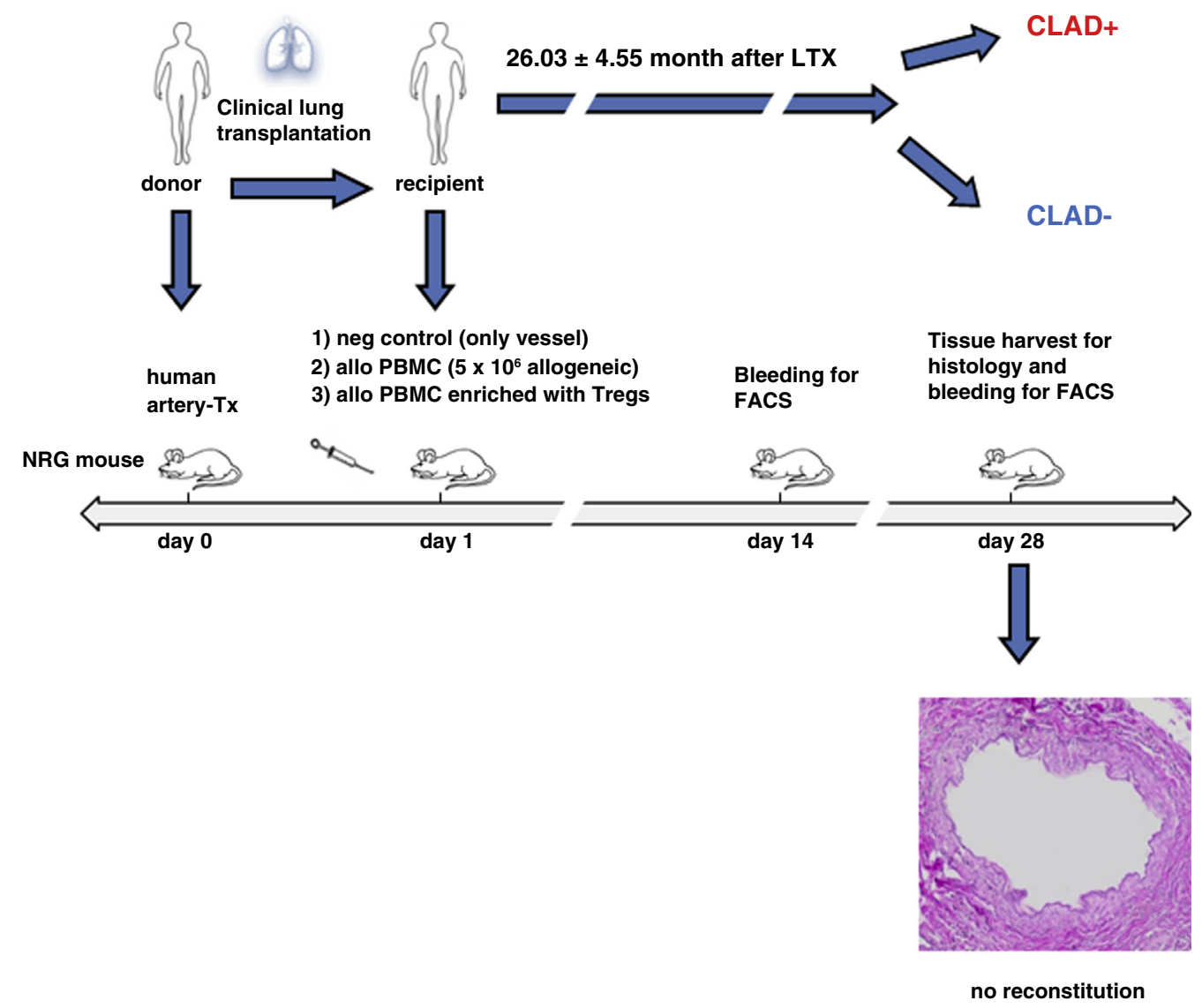

FIGURE 1. Design of the humanized adoptive transfer model in immune-deficient mice. Aortic interposition grafts in mice were performed with human pericardiacophrenic artery from surplus tissue of human lung grafts implanted into the infrarenal abdominal aorta of NODrag ${ }^{-/-} / \mathrm{IL}_{-}-2 \mathrm{r} \mathrm{c}^{-/-}(N R G) \mathrm{mice}$. On day $1,5 \times 10^{6}$ peripheral blood mononuclear cells $(P B M C s)$ from the respective lung recipient were injected intraperitoneally into murine hosts. Human PBMC engraftment in NRG mice was assessed by fluorescence-activated cell sorting (FACS) analyses of peripheral blood 28 days after PBMC reconstitution. Human artery grafts were harvested from mice 28 days after transplantation. LTX, Lung transplant; CLAD, chronic lung allograft dysfunction.

PBMC in mice were quantified by human CD45 staining in peripheral blood (Figure 3).

Experimental animals were later classified according to the presence or absence of CLAD of the respective recipients between 21 and 31 months posttransplantation. The CLAD- group $(\mathrm{n}=9)$ represents mice that received $5 \times 10^{6}$ allogeneic PBMC from recipients who were still CLAD-free $25 \pm 5$ months after lung transplantation and the CLAD + group $(n=9)$ represents mice reconstituted with PBMCs from lung recipients with CLAD development $23 \pm 5$ months after lung transplantation. Human PBMCs were followed in mice by staining for human-specific CD45 in peripheral blood (Figure 3, A). In all animals high frequencies of human CD45+ leukocytes were detected indicating efficient reconstitution (Figure 3, B). Also, high percentages of human $\mathrm{CD} 4{ }^{+} \mathrm{CD} 25^{+} \mathrm{CD} 127^{\text {low }}$ Treg were found in humanized mouse spleens 28 days after cell transfer without statistically significant differences between the groups (Figure 4, $A$ and $B$ ).
In Vivo Development of TA Reflects the Peripheral Treg Phenotype of the Lung Recipient and Is Most Pronounced in Recipients With CLAD Development After 2 Years

We then aimed to establish a link between development of TA in humanized mice and the peripheral Treg phenotype in lung transplantation recipients and compared recipients with CLAD manifestation after 2 years with those without CLAD. We have previously shown that higher frequencies of specific Treg subpopulations early after lung transplantation are protective against CLAD development. ${ }^{18} \mathrm{We}$ grouped the humanized mouse experiments according to higher or lower frequencies of these putative Treg populations in peripheral blood of the respective clinical lung recipients with an without CLAD occurrence at 2 years after transplantation (Figure 5). All 22 patients with complete data on peripheral blood Treg frequency before transplantation and 3 weeks and 3 months after transplantation and with corresponding humanized mice were included in 
PBMC

A

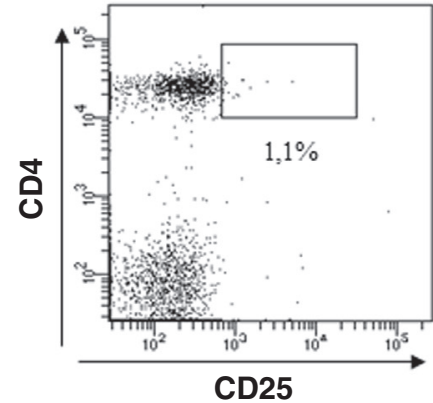

PBMC

CD4/25enrich.

B

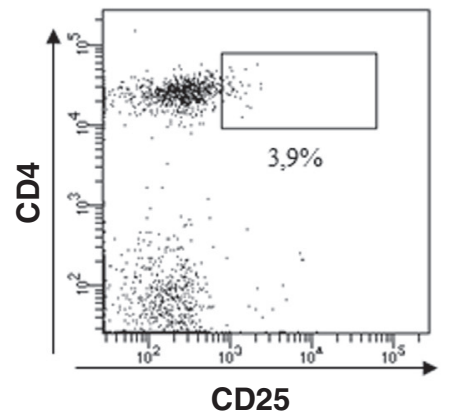

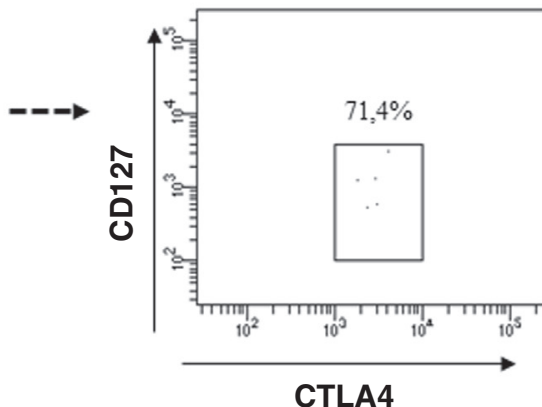

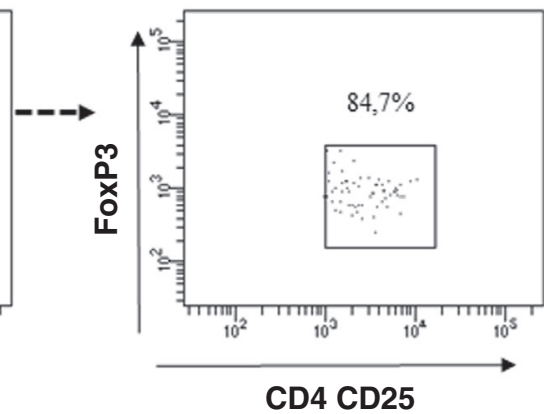

CD4 CD25

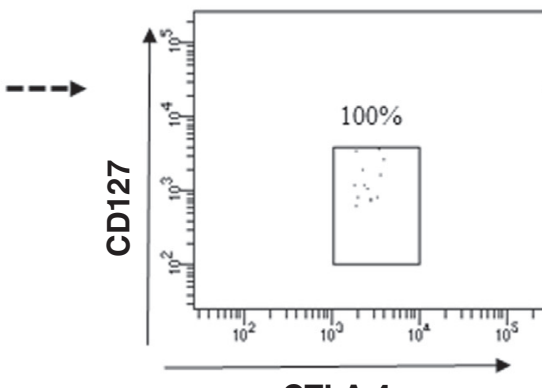

CTLA 4

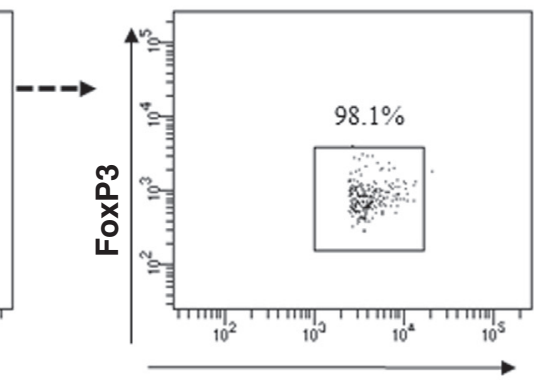

CD4 CD25

FIGURE 2. Representative characterizations of human peripheral blood mononuclear cell (PBMC) preparations immediately before intraperitoneal transfer into murine hosts. A, Multicolor fluorescence-activated cell sorting (FACS) of unmodified human PBMC to be adoptively transferred into mice of the PBMC group. Left panel, cluster of differentiation $(C D) 4^{+} \mathrm{CD} 25^{\text {high }}$ cells in the lymphocyte gate. Middle panel, within the $\mathrm{CD} 4{ }^{+} \mathrm{CD} 25^{\text {high }}$ gate, the majority of $\mathrm{CD} 127^{\text {low }}$ cells also were positive for cytotoxic T-lymphocyte-associated antigen 4 (CTLA4). Right panel, slightly less than one quarter of the $\mathrm{CD}^{+} \mathrm{CD} 25^{\text {high }}$ cells were also FoxP3 ${ }^{+}$. B, multicolor FACS of $5 \times 10^{6}$ human PBMC enriched with $6,7 \times 10^{5}$ autologous $\mathrm{CD} 4^{+} \mathrm{CD} 25^{\text {high }}$ cells to be adoptively transferred into mice of the PBMC CD4/25 enriched group. Left panel, higher frequencies of CD4 ${ }^{+} \mathrm{CD} 25^{\text {high }}$ cells in the lymphocyte gate. Middle panel, within the $\mathrm{CD} 4{ }^{+} \mathrm{CD} 25^{\text {high }}$ gate, more cells were $\mathrm{CD} 127^{\text {low }}$ and also positive for staining against CTLA4. Right panel, An increased percentage of the $\mathrm{CD} 4^{+} \mathrm{CD} 25^{\text {high }}$ cells were also $\mathrm{FoxP}^{+}$.

this analysis. Lung recipients without CLAD showed higher frequencies of $\mathrm{CD} 4{ }^{+} \mathrm{CD} 25^{\text {high }} \mathrm{CD} 127^{\text {low }}$ cells in the lymphocyte gate, compared with those with CLAD development with lower frequencies of $\mathrm{CD} 4{ }^{+} \mathrm{CD} 25^{\text {high }} \mathrm{CD} 127^{\text {low }}$ cells at early postoperative time points (Figure 5, B). Lung recipients without CLAD also showed high frequencies of $\mathrm{CD} 4{ }^{+} \mathrm{CD} 25^{\text {high }} \mathrm{FoxP}^{+} \mathrm{T}$ cells early after transplantation (Figure 5, B).

\section{In Vivo Development of TA Reflects CLAD Development in Patients Years Later}

We aimed to establish a link between development of TA in humanized mice at the time of transplantation and later CLAD in lung recipients. We have previously shown that alloantigen priming in clinical lung transplant recipients leads to more severe TA in a humanized mouse model. ${ }^{18}$ We grouped the humanized mouse experiments according to CLAD development of the respective clinical lung recipients at $24 \pm 5$ months after transplantation (Figure 5). All 22 patients with complete data on CLAD development at $25 \pm 5$ months after transplantation and with corresponding humanized mice were included into this analysis and representative histology images are shown in Figure 5, A. The TA development in humanized mice injected with PBMCs from patients without CLAD development within $25 \pm 5$ months after lung transplant was significantly less severe $(19 \%)$ than in mice reconstituted with PBMCs from lung recipients with CLAD $23 \pm 5$ months after lung transplantation (42\%) (Figure 5, $C)(P=.015$, analysis of variance). Enriching the PBMC transferred with autologous $\mathrm{CD} 4{ }^{+} \mathrm{CD} 25^{\text {high }+}$ cells did significantly suppress the development of TA in humanized mice, here, in both CLAD+ and CLAD- groups without significant differences between the 2 groups.

\section{DISCUSSION}

In this study, we show evidence that peripheral leukocytes from clinical lung transplant recipients who later developed CLAD transfer proinflammatory properties leading to TA in a humanized mouse model already at the time transplantation. In this model, PBMCs of lung transplantation recipients with later CLAD development elicit TA in small arteries procured from the lung donor. In this allogeneic setting and in the absence of pharmacologic 


\section{blood}

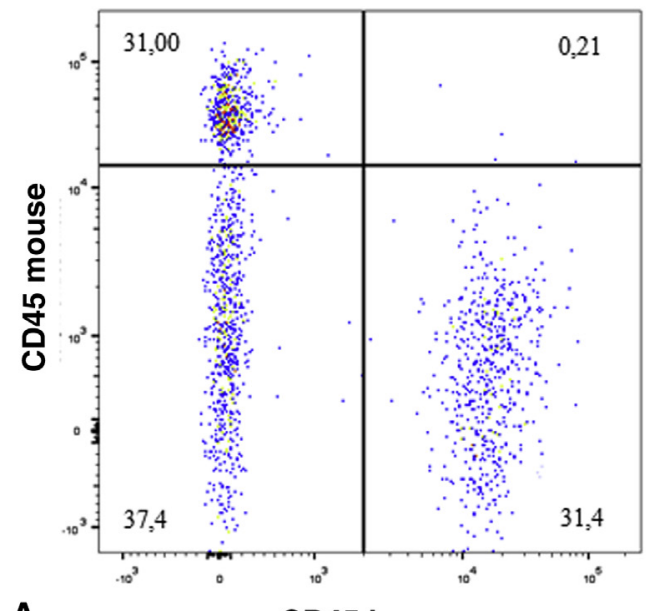

spleen

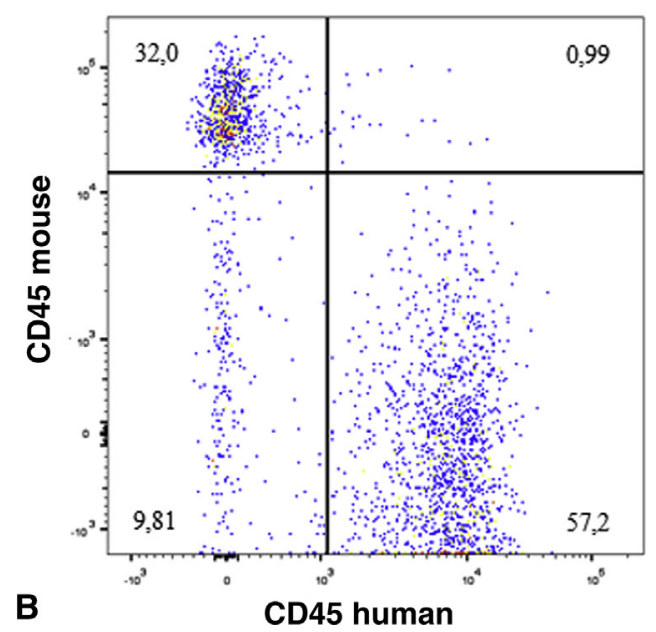

FIGURE 3. Monitoring of human leukocyte engraftment in murine hosts. A, Representative fluorescence-activated cell sorting (FACS) plot of a humanized mouse peripheral blood sample drawn on postoperative day 28 after human vessel transplantation and concomitant injection of allogeneic human peripheral blood mononuclear cells (PBMCs). Cells were stained with allophycocyanin-conjugated antimurine cluster of differentiation $(C D) 45$ monoclonal antibody $(\mathrm{mAb})$ and purified antiphycoerythrin-conjugated antihuman CD45 mAb. B, For further study of human cell engraftment, human CD45 ${ }^{+}$cells were stained in cell suspensions processed from mouse spleens harvested at day 28 after transplantation.

immunosuppression in humanized mice, severe TA develops following transfer of human alloreactive T cells, promoting endothelial luminal obstruction. Circulating peripheral blood Treg, procured at the time of lung transplantation, suppress rejection of donor-specific artery grafts in this setting.

Previously, several authors showed the important advantage of the artery transplantation model for the assessment and quantification of TA using morphometric measurements of the intimal hyperplasia in histology sections. ${ }^{16,19-21}$ In comparison, the heterotopic bronchus transplantation model does not produce continuous data, but rather a score built from a point system. ${ }^{22,23}$ Moreover, the availability of human bronchus that has been sampled through size reduction during transplantation ${ }^{24}$ or lung biopsy cannot be ensured to be legitimate. Small arteries, alternatively, are universally available from surplus pericardial tissue during lung transplantations.
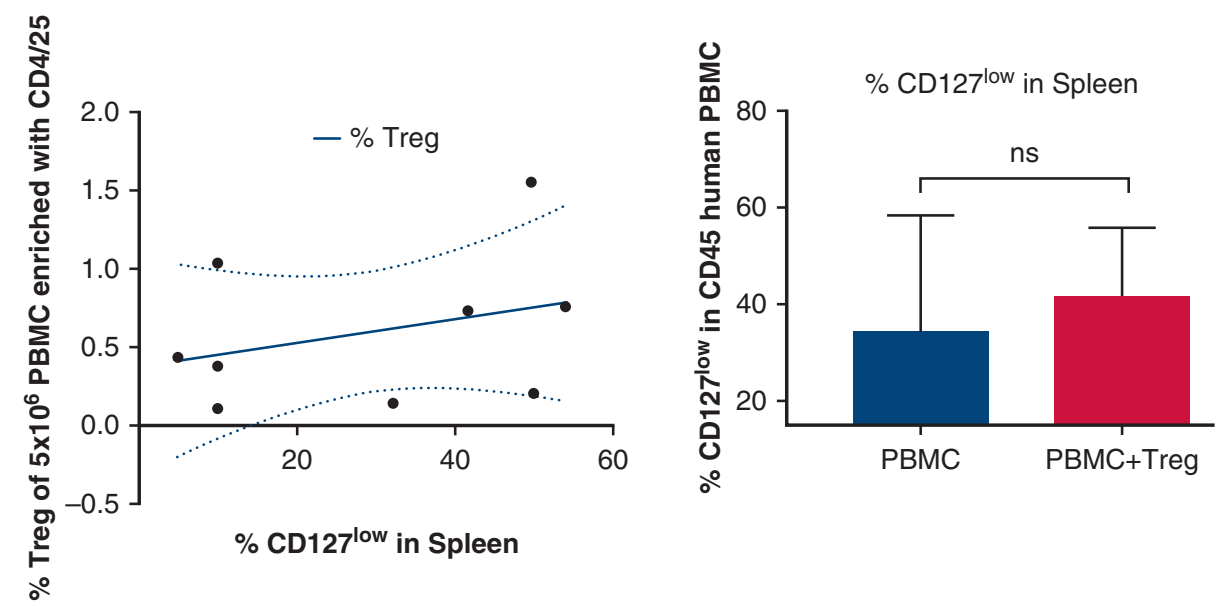

A

B

FIGURE 4. A, Monitoring of human regulatory T cells (Treg) engraftment in spleen of NODrag ${ }^{-1-} / \mathrm{IL}-2 \mathrm{r} \gamma \mathrm{c}^{-/-}$mice. After 28 days, a fluorescence-activated cell sorting analysis of explantated spleens were done to compare among of human cluster of differentiation $(C D) 127^{\text {low }}$ cells in correlation of the primary injected Tregs. B, Percentage of CD $127^{\text {low }}$ in spleen: human CD127 $7^{\text {low }}$ was quantified in spleen of mice. Concentrations of CD127 $7^{\text {low }}$ in spleens of mice were measured 28 days after transplantation. CD127 ${ }^{\text {low }}$ was elevated in peripheral blood mononuclear cells $(P B M C)$ chronic lung allograft dysfunction group compared with lower concentrations in the PBMC group. 

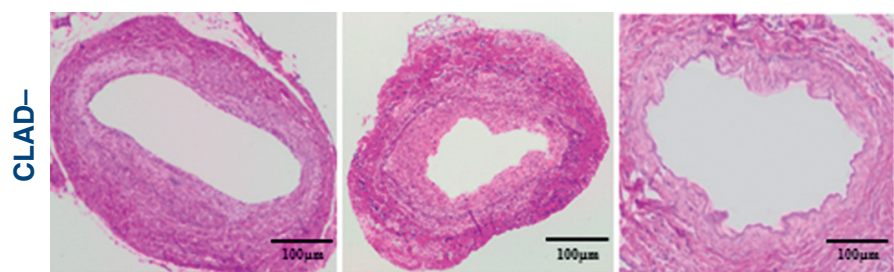

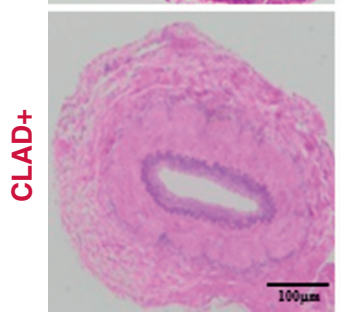

neg. control

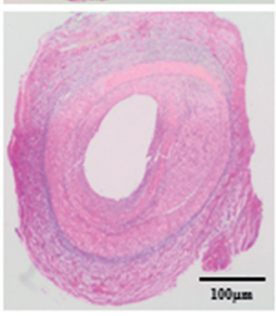

PBMC

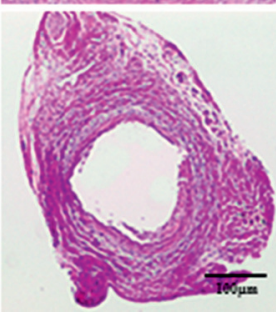

PBMC+Treg
A
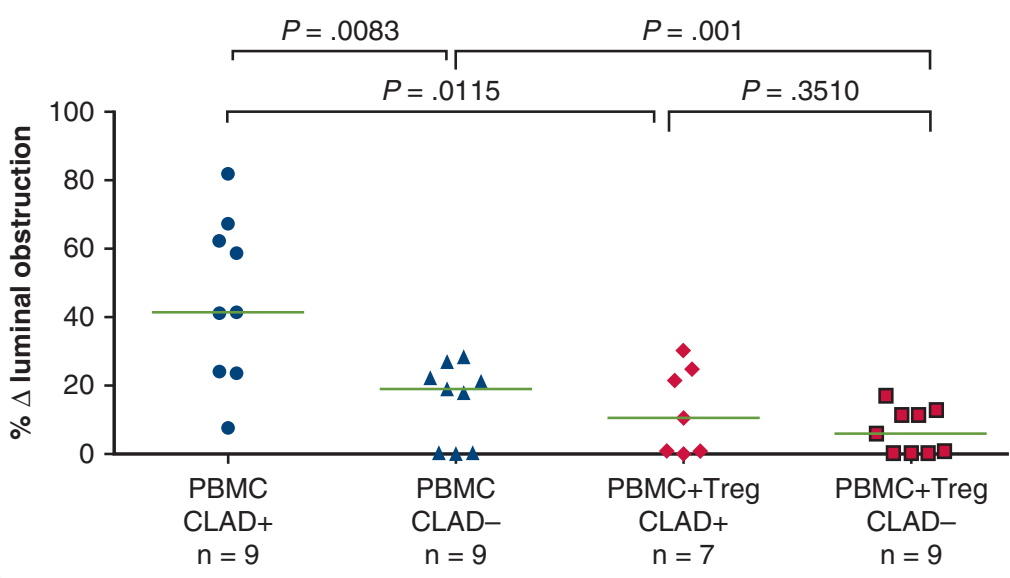
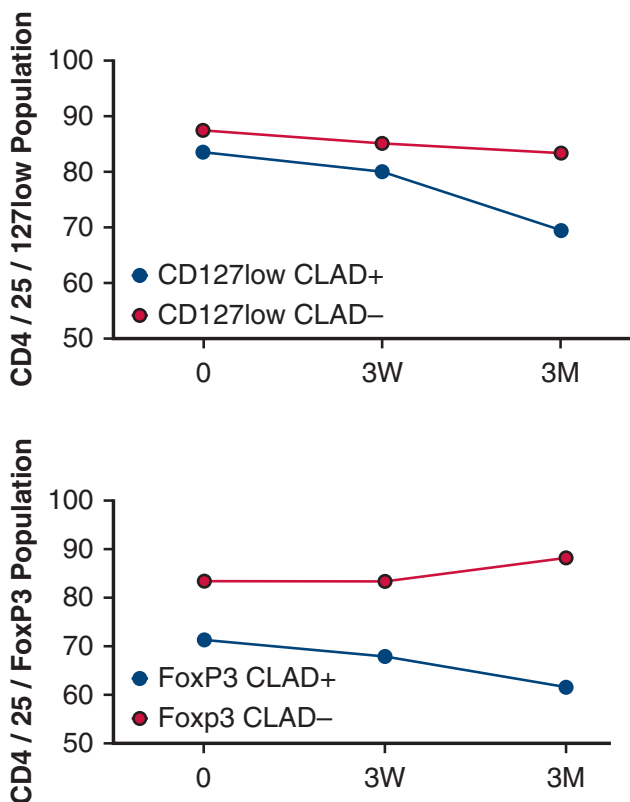

C

FIGURE 5. In vivo development of transplant arteriosclerosis reflects chronic lung allograft dysfunction (CLAD) development after transplantation. A, Representative histology sections of small human arteries transplanted into the abdominal aorta of $\mathrm{NODrag}^{-/} / \mathrm{IL}^{-2 \mathrm{rgc}^{-/}} \mathrm{mice}^{-}$were stained with Elastin-van-Giesson stain. Negative control animals were transplanted with a human artery procured from lung transplantation donor tissue and received no further treatment. Peripheral blood mononuclear cells $(P B M C s)$ group animals were also reconstituted with $5 \times 10^{6}$ human PBMCs from the respective lung transplant recipient. Animals in the PBMC cluster of differentiation $(C D) 4 / 25$ enrich group were reconstituted with $5 \times 10^{6}$ human PBMC enriched with 1.15 to $4.8 \times 10^{5}$ autologous $\mathrm{CD} 4{ }^{+} \mathrm{CD} 25^{\text {high }} \mathrm{T}$ cells from the respective lung recipient. The reconstitutions were either performed at the time of lung transplantation with CLAD-PBMCs from recipients who later were still CLAD-free $26 \pm 4.6$ months after lung transplantation or from recipients who later developed CLAD at $22 \pm 5.5$ months after lung transplantation. The human artery was harvested for histology 28 (naïve groups). B, Regulatory T cell (Treg) frequencies divided into percentage of $\mathrm{CD} 4{ }^{+} \mathrm{CD} 25^{\text {high }} \mathrm{FoxP} 3^{+}, \mathrm{CD} 4^{+} \mathrm{CD} 25^{\text {high }} \mathrm{CD} 127^{\text {low }}$ in all lymphocytes at 5 different time points. Peripheral whole blood samples were drawn immediately before transplantation, 3 weeks, 3 months, and 6 months after transplantation. CD $4^{+} \mathrm{CD} 25^{\text {high }}$ cells were phenotyped by surface staining for CD127 and intracellular staining for FoxP3. Lung recipients without CLAD showed higher frequencies of CD4 ${ }^{+} \mathrm{CD} 25^{\text {high }} \mathrm{C}$ D $127^{\text {low }}$ cells in the lymphocyte gate, compared with those with CLAD development with lower frequencies of $\mathrm{CD} 4{ }^{+} \mathrm{CD} 25^{\text {high }} \mathrm{CD} 127^{\text {low }}$ cells at early postoperative time points. Similarly, lung recipients without CLAD also showed high frequencies of $\mathrm{CD} 4{ }^{+} \mathrm{CD} 25^{\text {high }} \mathrm{FoxP}^{+} \mathrm{T}$ cells early after transplantation. C, Morphometric measurements of intimal hyperplasia as quantification of transplant arteriosclerosis (TA) are expressed as percentage luminal obstruction and mean values with standard deviation are given. TA was significantly more severe in the CLAD+ PBMC than CLAD- PBMC group. In both the CLAD + and the CLAD- experiments, enrichment with autologous CD $4^{+} \mathrm{CD} 25^{\text {high }} \mathrm{T}$ cells significantly suppressed TA to baseline levels (analysis of variance; $P<.05$; individual Bonferroni post hoc test results are given).

The degree of TA we observed in mice having been reconstituted with CLAD- PBMC from recipients who were later still CLAD-free $26 \pm 4.6$ months after lung transplantation was severe, but it was significantly more severe upon transfer of PBMC CLAD+ from recipients who later developed CLAD at $22 \pm 5.5$ months after lung transplantation.

The first advantage concerns the availability of donor tissue. Moreover in our experimental setting, each lung recipient had a respective mice model suggesting better 
homogeneity and traceability within experimental groups. The finding of strong Treg function in PBMC procured from lung transplantation recipients with later development of CLAD opens up another set of questions regarding the Treg phenotype prevalent in the peripheral blood of patients. Bhorade and colleagues ${ }^{25}$ show a lower percentage of $\mathrm{CD}^{+}{ }^{+} \mathrm{FoxP}_{3}{ }^{+}$cells in the BAL fluid of lung transplant recipients who eventually develop bronchiolitis obliterans syndrome (BOS) compared with those who remain stable, suggesting that higher percentage of $\mathrm{FoxP}^{+}$cells among $\mathrm{CD}^{+}{ }^{+}$cells in the BAL fluid during acute rejection episodes may protect against development of BOS or promote the return of allograft stability. Contrary to these results, Krustup and colleagues ${ }^{26}$ demonstrated in a similar BAL fluid study that $\mathrm{FoxP}^{+}$cells in lung allografts did not correlate with BOS-free survival time. These controversial results may show a lack of consistence in the methods. Moreover, they failed to show the correlation in peripheral blood.

Gregson and colleagues ${ }^{27}$ published a study in 47 recipients, 13 of whom eventually developed BOS, showing that a certain Treg subset, $\mathrm{CCR} 7^{+} \mathrm{CD} 3{ }^{+} \mathrm{CD} 4{ }^{+} \mathrm{CD} 25^{\text {high }}$ FoxP3 ${ }^{+} \mathrm{CD}^{2} 5 \mathrm{RA}^{-}$lymphocytes, in BAL fluid is negatively correlated with later occurrence of BOS. Again, a correlation showing the same trend for Tregs in peripheral blood was not performed. The herein described humanized mouse model enables further uses, including the study of leukocyte involvement in the development of primary graft dysfunction and the mechanisms of donor-specific antibody-mediated damage to allogeneic tissues.

\section{Limitations}

The human immune system reconstituted in NRG mice by adoptive transfer of PBMCs represents mainly the $\mathrm{T}$ cell compartment, whereas other components of the immune system, such as B cells or neutrophils, are less well represented. Thus, effects of other cellular compartments of the immune system on the development of rejection may not be studied.

Because human small bronchus tissue is only infrequently available in the course of lung transplantations, we were prompted to design the study as a humanized aorta transplant model assuming a substantial overlap in the immunologic events involved in the development of TA and CLAD. There remains a risk of overinterpreting the similarities between TA in humanized mice and CLAD in human patients. Another limitation of this study is the low sample numbers of sera for cytokine measurements, which did not allow for sufficient statistical analyses.

\section{CONCLUSIONS}

Lung transplant recipients who later develop CLAD have peripheral leukocytes and/or donor vessel endothelium already at the time of transplant that transfer proinflammatory properties leading to TA in a humanized mouse model.
TA remains sensitive to inhibition by autologous regulatory T cells, suggesting a cell therapy-based approach for the prevention and treatment of CLAD after lung transplantation.

\section{Webcast}

You can watch a Webcast of this AATS meeting presentation by going to: https://aats.blob.core.windows.net/ media/17AM/2017-05-02/RM306/05-02-17_Room306_ 0750_Siemeni.mp4.

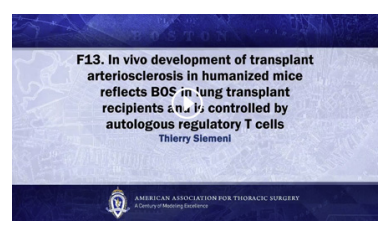

\section{Conflict of Interest Statement}

Authors have nothing to disclose with regard to commercial support.

Dale Greiner, PhD, donated the NODrag ${ }^{-1-} / \mathrm{IL}^{-} 2 \mathrm{r} \gamma \mathrm{c}^{--}$mice used in this study.

\section{References}

1. Todd JL, Palmer SM. Bronchiolitis obliterans syndrome: the final frontier for lung transplantation. Chest. 2011;140:502-8.

2. Balsara KR, Krupnick AS, Bell JM, Khiabani A, Scavuzzo M, Hachem R, et al. A single-center experience of 1500 lung transplant patients. J Thorac Cardiovasc Surg. 2018;156:894-905.

3. Verleden SE, Todd JL, Sato M, Palmer SM, Martinu T, Pavlisko EN, et al. Impact of CLAD phenotype on survival after lung retransplantation: a multicenter study. Am J Transplant. 2015;15:2223-30.

4. Verleden GM, Raghu G, Meyer KC, Glanville AR, Corris P. A new classification system for chronic lung allograft dysfunction. J Heart Lung Transplant. 2014;33: 127-33.

5. Lund LH, Edwards LB, Kucheryavaya AY, Benden C, Christie JD, Dipchand AI, et al. The registry of the International Society for Heart and Lung Transplantation: thirty-first official adult heart transplant report—2014; focus theme: retransplantation. J Heart Lung Transplant. 2014;33:996-1008.

6. Sato M, Ohmori-Matsuda K, Saito T, Matsuda Y, Hwang DM, Waddell TK, et al. Time-dependent changes in the risk of death in pure bronchiolitis obliterans syndrome (BOS). J Heart Lung Transplant. 2013;32:484-91.

7. Jonigk D, Rath B, Borchert P, Braubach P, Maegel L, Izykowski N, et al. Comparative analysis of morphological and molecular motifs in bronchiolitis obliterans and alveolar fibroelastosis after lung and stem cell transplantation. J Pathol Clin Res. 2017;3:17-28

8. Angelini A, Castellani C, Fedrigo M, de Boer OJ, Meijer-Jorna LB, Li X, et al Coronary cardiac allograft vasculopathy versus native atherosclerosis: difficulties in classification. Virchows Arch Int J Pathol. 2014;464:627-35.

9. Castellani C, Angelini A, de Boer OJ, van der Loos CM, Fedrigo M, Frigo AC, et al. Intraplaque hemorrhage in cardiac allograft vasculopathy. Am J Transplant. 2014; $14: 184-92$

10. Tsutsui H, Ziada KM, Schoenhagen P, Lyisoy A, Magyar WA, Crowe TD. Lumen loss in transplant coronary artery disease is a biphasic process involving early intimal thickening and late constrictive remodeling: results from a 5-year serial intravascular ultrasound study. Circulation. 2001;104:653-7.

11. Russell ME, Wallace AF, Wyner LR, Newell JB, Karnovsky MJ. Upregulation and modulation of inducible nitric oxide synthase in rat cardiac allografts with chronic rejection and transplant arteriosclerosis. Circulation. 1995;92:457-64.

12. Siemeni T, Knöfel A-K, Madrahimov N, Sommer W, Avsar M, Salman J, et al In vivo development of transplant arteriosclerosis in humanized mice reflects alloantigen recognition and peripheral Treg phenotype of lung transplant recipients. Am J Transplant. 2016;16:3150-62. 
13. Berastegui C, Gómez-Ollés S, Sánchez-Vidaurre S, Culebras M, Monforte V, López-Meseguer M, et al. BALF cytokines in different phenotypes of chronic lung allograft dysfunction in lung transplant patients. Clin Transplant. 2017; 31:e12898.

14. Berastegui C, Román J, Monforte V, Bravo C, López-Meseguer M, Montero MA, et al. Biomarkers of pulmonary rejection. Transplant Proc. 2013;45:3163-9.

15. Kastelijn EA, Rijkers GT, Van Moorsel CHM, Zanen P, Kwakkel-van Erp JM, Van De Graaf EA, et al. Systemic and exhaled cytokine and chemokine profiles are associated with the development of bronchiolitis obliterans syndrome. J Heart Lung Transplant. 2010;29:997-1008.

16. Koulack J, McAlister VC, Giacomantonio CA, Bitter-Suermann H, MacDonald AS, Lee TD. Development of a mouse aortic transplant model of chronic rejection. Microsurgery. 1995;16:110-3.

17. Braun M, Müller B, ter Meer D, Raffegerst S, Simm B, Wilde S, et al. The CD6 scavenger receptor is differentially expressed on a CD56 natural killer cell subpopulation and contributes to natural killer-derived cytokine and chemokine secretion. J Innate Immun. 2011;3:420-34.

18. Salman J, Ius F, Knoefel A-K, Sommer W, Siemeni T, Kuehn C, et al. Association of Higher CD4(+) CD25(high) CD127(low), FoxP3(+), and IL-2(+) T cell frequencies early after lung transplantation with less chronic lung allograft dysfunction at two years. Am J Transplant. 2017;17:1637-48.

19. Nadig SN, Więckiewicz J, Wu DC, Warnecke G, Zhang W, Luo S, et al. In vivo prevention of transplant arteriosclerosis by ex vivo expanded human regulatory $\mathrm{T}$ cells. Nat Med. 2010;16:809-13.

20. Wood KJ, Goto R. Mechanisms of rejection: current perspectives. Transplantation. 2012;93:1-10.

21. Warnecke G, Feng G, Goto R, Nadig SN, Francis R, Wood KJ, et al. CD4+ regulatory T cells generated in vitro with IFN- $\gamma$ and allogeneic APC inhibit transplant arteriosclerosis. Am J Pathol. 2010;177:464-72.

22. Boehler A, Chamberlain D, Kesten S, Slutsky AS, Liu M, Keshavjee S. Lymphocytic airway infiltration as a precursor to fibrous obliteration in a rat model of bronchiolitis obliterans. Transplantation. 1997;64:311-7.

23. Sommer W, Knöfel A-K, Madrahimov N, Avsar M, Jonigk D, Salman J, et al. Allogeneic CD4+CD25high T cells regulate obliterative bronchiolitis of heterotopic bronchus allografts in both porcinized and humanized mouse models. Transplantation. 2015;99:482-91.

24. Date H, Aoyama A, Hijiya K, Motoyama H, Handa T, Kinoshita H, et al. Outcomes of various transplant procedures (single, sparing, inverted) in livingdonor lobar lung transplantation. J Thorac Cardiovasc Surg. 2017;153:479-86.

25. Bhorade SM, Chen H, Molinero L, Liao C, Garrity ER, Vigneswaran WT, et al. Decreased percentage of CD4+FoxP3+ cells in bronchoalveolar lavage from lung transplant recipients correlates with development of bronchiolitis obliterans syndrome. Transplantation. 2010;90:540-6.

26. Krustrup D, Iversen M, Martinussen T, Schultz HHL, Andersen CB. The number of FoxP3 + cells in transbronchial lung allograft biopsies does not predict bronchiolitis obliterans syndrome within the first five years after transplantation. Clin Transplant. 2015;29:179-84.

27. Gregson AL, Hoji A, Palchevskiy V, Hu S, Weigt SS, Liao E, et al. Protection against bronchiolitis obliterans syndrome is associated with allograft CCR7+ CD45RA- T regulatory cells. PloS One. 2010;5:e11354.

Key Words: lung transplant, rejection, regulatory $\mathrm{T}$ cells

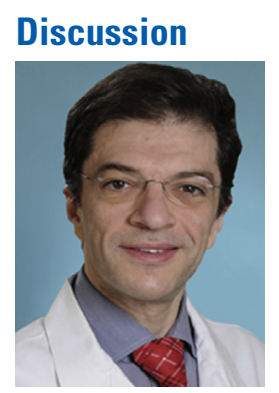

Dr Daniel Kreisel (St Louis, Mo). Congratulations on your nice presentation and thank you for sending me the paper in advance. Your group published this model in The American Journal of Transplantation in 2016, and this current work represents a very nice and elegant model to study the responses of cells isolated from lung transplant recipients in vivo. Your results suggest that the development of transplant arteriosclerosis in humanized mice correlates with the development of chronic lung allograft dysfunction (CLAD) in human lung recipients and that regulatory $\mathrm{T}$ cells may inhibit the development of graft pathology.

I have 3 questions. Similar work by Jordan Pober from Yale University demonstrated several years ago that interferon gamma is critical for the development of transplant arteriosclerosis in similar models. More recent work by David Wilkes and others in both mice and humans have suggested that interleukin 17, on the other hand, is a contributing factor to the develop of CLAD. Given the differences in pathogenesis based on these studies, could you discuss the validity of your model to predict CLAD in human lung recipients?

Dr Thierry Siemeni (Hannover, Germany). You see that we also studied the effect of interferon gamma on these subsets, and we also observed that we were able to show that transplant arteriosclerosis was in these cases with the higher effect or higher level of interferon gamma. And about interleukin 17, we didn't have a complete study about that.

Dr Kreisel. Work by Jonathan Baumberg a few years ago in pancreatic islet transplant showed that the trafficking of the regulatory $\mathrm{T}$ cells to the secondary lymphoid organs was critical to mediate immunoregulation. Work from our laboratory has shown that accumulation of regulatory $\mathrm{T}$ cells in the lung allograft itself is important and the regulation in lung transplant may occur locally.

Do you have any data in your model regarding the trafficking of the regulatory T cells? Did you do any immunostaining of low cytometry to evaluate where the regulatory $\mathrm{T}$ cells accumulate?

Dr Siemeni. We previously, about 2 years ago, published data about transplantation of autologous bronchi in mice, and we also have some subsets where we were able to demonstrate the level of bronchiolitis obliterans syndrome was corresponding with subsequent deaths in those cases.

Dr Kreisel. Finally, you showed that the enrichment with regulatory $\mathrm{T}$ cells leads to a modest increase in the percentage of regulatory $\mathrm{T}$ cells, from $1.7 \%$ to $3.4 \%$, in the slide you showed, and in the group of CLAD peripheral blood mononuclear cells without adoptive transfer of regulatory $\mathrm{T}$ cells, I imagine you have a range of percentages of regulatory $\mathrm{T}$ cells. Did you see a correlation between the percentage of regulatory $\mathrm{T}$ cells and luminal obstruction given that the difference was only $1.7 \%$ to $3.4 \%$ ?

Dr Siemeni. No. We just had a higher level of regulatory $\mathrm{T}$ cells and then we just observed that the luminal obstruction was less but not coordinating with the level of the difference.

Dr Kreisel. But I imagine in your group where you don't adoptively transfer regulatory $\mathrm{T}$ cells, you have a span from, let's say, $1 \%$ to $2.5 \%$, which is not much lower than what you show with the enrichment of the regulatory $\mathrm{T}$ cells, but yet the differences in luminal obstructions are quite drastic. 
Dr Siemeni. It's high, yes, it's drastic. But to compare this study with other studies we have done on pigs and on bronchi on humans, it was almost the same. The difference between the group with additional regulatory $\mathrm{T}$ cells or without regulatory $\mathrm{T}$ cells, we didn't observe a really big difference between the 2 groups. But at the end with additional regulatory $\mathrm{T}$ cells we were able to see a high difference between the 2 groups.

Dr Kreisel. So you think the enrichment of regulatory T cells mediated an effect beyond the regulatory $\mathrm{T}$ cells that are present in your peripheral blood mononuclear cells?

Dr Siemeni. Yes, although I think it is also not proportional. So maybe $1 \%$ or $2 \%$ means a little bit more than in the 1 case than we think.

Dr Kreisel. Thank you. Congratulations.

Dr Siemeni. Thank you.

Dr Thomas M. Egan (Chapel Hill, NC). Thank you for a nice presentation. I'm curious if this turns out to be validated, how could you use this information to treat patients? In other words, so now you have a predictor of an increased hazard for development of CLAD. How would you use that going forward in a clinical situation?
Dr Siemeni. We first start with a clinical setting and then observe the patient, and after 2 years we just separate the groups. So after 2 years we just observe, okay, we have 1 group with CLAD patients and the other group without CLAD patients. So we discovered it afterward.

Dr Egan. No, but I mean going forward, if you knew that patients were at risk, what would you be able to do?

Dr Siemeni. That's a good question. We have ongoing studies on that. We also tried to introduce the fact that we are going to be able to use the regulatory $\mathrm{T}$ cells on humans. We started about 6 months a prospective randomized study to get some more information about that.

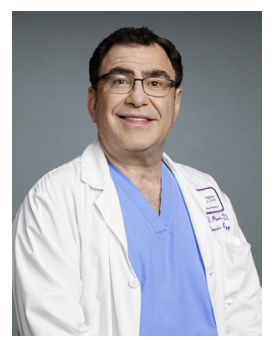

Dr Harvey I. Pass (New York, NY). So wouldn't you really need to longitudinally look at flow patterns in your transplanted patients over time to see what the levels of the regulatory $\mathrm{T}$ cells are and see if that correlates?

Dr Siemeni. Yes. 